\section{ECRR Outside the} Library

\section{Providing Meaningful Family-Focused Community Outreach}

Kathlleen Campana, J. Elizabeth Mills, and Or. Michelle H. Marrin

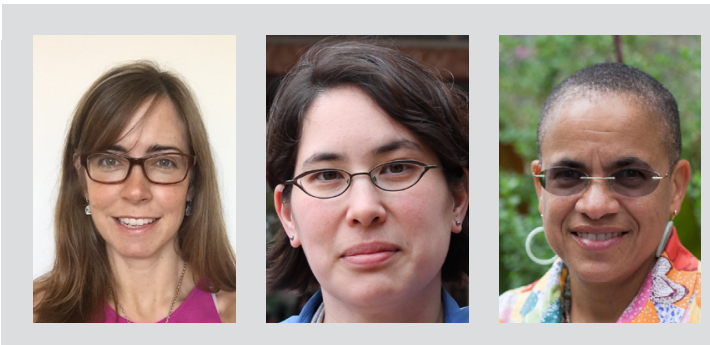

Kathleen Campana is a Lecturer at Kent State University's School of Information and a PhD Candidate at University of Washington's Information School. Her research focuses on understanding the learning that occurs for children and youth in informal learning environments and how the environment influences their learning. J. Elizabeth Mills is a PhD Candidate at the University of Washington iSchool. She has a background in children's book publishing, both as an editor and as an author. She recently worked as a researcher on Project VIEWS2, a study of early literacy outcomes in public library storytimes. Dr. Michelle H. Martin is the Beverly Cleary Endowed Professor for Children and Youth Services in the Information School at the University of Washington and from 2011 to 2016 was the inaugural Augusta Baker Endowed Chair in Childhood Literacy at the University of South Carolina.
$\mathrm{D}$ o you want to reach and support ALL families in your community, especially those who are underserved, but feel like you are not reaching them through your in-house programs and services?

Have you tried moving your programs and services out to community locations to reach these families where they are? In Project LOCAL (Library Outreach as a Community Anchor in Learning), an Institute of Museum and Library Services-funded National Leadership planning grant, we found that by moving programs out into the community and adapting them for particular settings, libraries are reaching families in many underserved communities.

Through interviews and focus groups as part of Project LOCAL, we learned that active, staff-led outreach programs are crucial for reaching families in underserved communities and helping to support learning for the entire family. In fact, these active programs can serve as natural environments for the five Every Child Ready to Read (ECRR) practices: talking, reading, singing, playing, and writing. Examples of such programs include the following:

- Storytimes at community day cares

- Summer reading/learning programs at summer meal sites, parks, and other community locations

- Prime Time Family Reading Time

- Learning/literacy-focused programs in housing developments

- School-based storytime/library programs.

In these programs, librarians are incorporating a mixture of the ECRR practices into programs for both older and younger children. This is important because all children, not just those aged 0-5, can benefit from exposure to and interactions with talking, singing, reading, playing, and writing.

In addition to reaching children of all ages in underserved communities, many of these programs enable libraries to reach parents and caregivers as well, providing opportunities for libraries to model how to encourage and support learning for the children in their care. By reaching out to these parents and caregivers where they are to provide support and education on their child's learning, libraries can address the multiple barriers many of these communities face that prevent them from taking advantage of resources that would help them understand how best to support their child.

During our research, it also became apparent that libraries are not doing this work alone. Most of the time, libraries are utilizing partnerships with community organizations. These partnerships serve a variety of purposes, such as helping the library connect with families or helping with 
development and delivery of the programs. Libraries often lead these partnership efforts, bringing together multiple organizations in the community, demonstrating that they are an important part of the childhood learning community.

\section{Outreach at Your Library}

So what does outreach look like for your library? Are you reaching the families you want to reach? Do you want to increase these efforts, or are you just getting started? Many of the libraries we spoke with moved through four common phases (though not always in this order):

1. ENGAGE with communities and their needs. Many libraries are doing this through a variety of methods:
a. Surveys
b. Focus groups
c. Casual conversations
d. Census, educational, and other community-based sta- tistics

2. CULTIVATE partnerships. Some libraries are building new partnerships to reach their communities; others are leveraging existing partnerships but in different ways.

3. PROVIDE programs. Many librarians are offering innovative and unusual programs out in the community by identifying a community location, developing a structure for the program, and taking note of what is needed for the program.

a. Often the library will take the lead role by fully developing the program, working with their partners to determine locations, and determining the role each partner will play.

4. REFLECT on the programs. Though many libraries are not formally evaluating their outreach programs, they still use the following ways to understand the effectiveness of their work:
a. Trends in attendance numbers
b. Conversations with families and partners
c. Quick surveys

Figure 1 offers a preliminary visualization of how we see the phases in outreach production fitting together. The final phase of Project LOCAL includes a national survey, and we will continue to adapt this model as we analyze the data that emerges from this survey to deepen our understanding of how libraries are reaching outside of their walls to offer programs and services to families in underserved communities.

\section{Outreach and Advocacy}

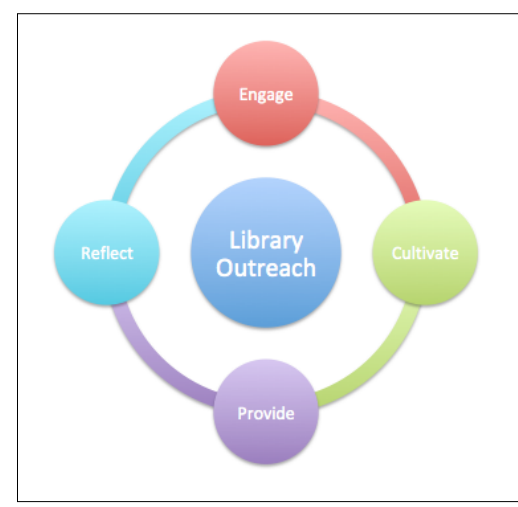

Figure 1. Preliminary Model of Outreach Production
In addition to reaching children and families in underserved communities, these programs can have other benefits. When you talk, sing, read, play, and write to encourage learning and skillbuilding, you also provide opportunities to expose your community partners to the importance of these practices, helping them understand ways that they can encourage learning for children who interact with their organization.

Furthermore, the work can demonstrate to the partners how the library brings expertise to their services and to the community as a whole. This may help open up advocacy opportunities to strengthen and extend these partnerships by finding ways to collaborate around ECRR-driven programs and to provide ECRR training to their organization.

Building and extending partnerships around learning for children and families plays a crucial role in community life and the civic good of each partner involved. This work can empower the library to bring partners together and provide opportunities for the organizations to engage in co-learning, sharing their own institutional knowledge and working together to build new knowledge around learning for children and families.

The process of creating a web of partners allows the library to establish itself as a community anchor, committed to providing a strong layer of support that encourages learning for ALL children and their families in and outside of library walls.

So as you think about moving your programs and services out into the community and adapting them to where they are, keep in mind the powerful impact this work can have for the children, families, and partners involved; the position of the library in the community; and ultimately the community as a whole. ¿. 